\title{
Dietary supplementation with Aloe vera polysaccharide enhances the growth performance and immune function of weaned piglets
}

\author{
J. Qiao ${ }^{1,2,4}$, H.H. Li', Ch.J. Zheng', Z.Y. Feng ${ }^{2,3}$ and W. Wang ${ }^{1,4}$ \\ ${ }^{1}$ Tianjin Institute of Animal Husbandry and Veterinary Science, XiQing District Jinjing Road 17 km, Tianjin, 300384, P.R. China \\ ${ }^{2}$ China Agricultural University, National Key Laboratory of Animal Nutrition \\ No. 2 Yuanmingyuan West Road, Beijing, 100193, P.R. China \\ ${ }^{3}$ National Feed Engineering Technology Research Center Beijing, No. 2 Yuanmingyuan West Road, Beijing, 100193, P.R. China
}

KEY WORDS: Aloe vera polysaccharide, weaned piglet, growth performance, immunity function cytokine

Received: 7 January 2013

Revised: 9 September 2013

Accepted: 7 October 2013

${ }^{4}$ Corresponding author: e-mail: qiaojy1979@126.com

anist@vip.163.com

\begin{abstract}
This study was conducted to investigate the effects of crude Aloe vera polysaccharide (AVP) on the growth performance and immune function of weaned piglets. A total of 200 (Landrace Yorkshire $\times$ Duroc) weaned pigs at $21 \mathrm{~d}$ with initial $8.88 \pm 0.49 \mathrm{~kg}$ body weight (BW) were allotted to one of four dietary treatments in a randomized complete block design according to their sex and BW ( 5 replicates with 10 pigs per pen, 5 gilts and 5 barrows). Dietary treatments included one basal diet, and three diets with AVP supplementation $(0.05 \%, 0.1 \%$, or $0.2 \%)$. Average daily gain (ADG), average daily feed intake (ADFI), and feed:gain ( $F: G)$ ratios were calculated at the end of the experiment. Separated serum samples from each treatment were assayed at the end of the experiment for the concentrations of cytokines and the blocking rate of antibodies against classical swine fever virus (CSFV). Supplementation of AVP at $0.1 \%$ improved $(P<0.05)$ ADG compared with the control group. No significant differences in ADFI or F:G were observed between AVP-treated and untreated control piglets. All AVP-treated pigs had a significantly lower incidence of diarrhoea $(P<0.05)$ when compared with control pigs. Feeding AVP resulted in increasing $(P<0.01) \mathrm{IL}-2$ and IFN-y (at $0.1 \%$ and $0.2 \%$ ) and IL-4 (at $0.05 \%$, $0.1 \%$ and $0.2 \%)$, and in no significant changing of IL-10 $(P>0.05)$. Supplementation of AVP at $0.05 \%, 0.1 \%$ and $0.2 \%$ increased $(P<0.01)$ the blocking rate of antibodies against CSFV. These results indicate that dietary supplementation with dietary AVP enhanced growth performance in weaned piglets by improving immune function, decreasing the incidence of diarrhoea.
\end{abstract}

\section{Introdution}

Aloe vera is a tropical or sub-tropical plant with turgid lance-shaped green leaves with jagged edges and sharp points. The plant is a member of the lily family (Liliaceae), not the cactus family as many would believe from the rosette-like arrangement of the long spiked leaves on the central stem (Chow et al., 2005). One of its main biological components, Aloe vera polysaccharide (AVP), ex- hibits an immunostimulatory effect on human and animal cells (t'Hart et al., 1989; Pugh et al., 2001; $\mathrm{Yu}$ et al., 2009). Feed additives that leave no residue in animal products and do not cause drug resistance are being developed for replacement of antibiotics to avoid their negative effects. Astragalus polysaccharide and Acanthopanax senticosus extract have been used in weaned piglet diets for their immune enhancement, anti-microbial and growth promoting functions (Yuan et al., 2006; Yin et al., 
2008). Previous studies have shown that Aloe vera feed additive can 1 . significantly increase body weight, reduce the feed:gain ratio, and improve the meat quality of growing-finishing pigs (Qi et al., 2008); 2. enhance the immune functions of broilers (Dai et al., 2007); 3. improve the innate immune function of rats; 4. inhibit mechanically induced cough of cats (Šutovská, 2010). Little information has been reported, however, regarding the use of AVP in weaned piglets. Our experiment was conducted to investigate the effects of AVP on growth performance and immune function of weaned piglets to examine its usefulness in the pig industry.

\section{Material and methods}

All procedures involving animals were approved by the Animal Care and Use Committee of the Tianjin Academy of Agricultural Sciences.

\section{Experimental design, animals, housing and diets}

Two hundred newly weaned pigs (Landrace Yorkshire $\times$ Duroc; initial body weight $(\mathrm{BW})=8.88$ $\pm 0.49 \mathrm{~kg}$ ) were selected from a commercial pig farm (Henan, China). Pigs were allotted to one of four dietary treatments in a randomized complete block design according to their sex and BW (5 replicates with 10 pigs per pen, 5 gilts and 5 barrows). Dietary treatments included one basal diet (Table 1) and three diets with AVP supplementation $(0.05 \%, 0.1 \%$, and $0.2 \%$ ). All diets were formulated to meet the nutrient requirements recommended by the NRC (1998).

All piglets were inoculated intramuscularly at the age of 0 and 18 days with classical swine fever live vaccine (C-strain, rabbit origin, Guangzhou Winsun Pharmaceutical Co., Ltd, China). Each pen was provided with a stainless steel feeder and one nipple drinker that allowed for ad libitum access to feed and water throughout the experiment. Commercial AVP prepared by ethanol extraction from Aloe vera gel, was assayed at Beijing Key Laboratory of Plant Resources Research and Development, and the polysaccharide content was determined to be $48.55 \%$; the remainder mainly contained organic acids, oligosaccharides, monosaccharides, anthraquinone, and inorganic salts.

\section{Growth performance}

Body weight and feed intake were measured at the beginning and end of the trial. On the basis of these data, average daily gain (ADG), average daily feed intake (ADFI), and feed:gain (F:G) ratio were calculated for the period from 0 to 28 days. Health status was recorded throughout the experiment.
Table 1. Diet composition and chemical analysis of diets (as fed basis)

\begin{tabular}{ll}
\hline Indices & Amount \\
\hline Diet ingredient & $\%$ \\
maize, yellow & 61.06 \\
soyabean meal, 46\% CP & 20.00 \\
whey powder & 5.00 \\
fish meal, 65\% CP & 4.00 \\
soyacomil, 65\% CP & 2.50 \\
wheat middlings & 2.50 \\
glucose & 1.20 \\
acidifier & 0.30 \\
calcium hydrogen phosphate & 1.10 \\
limestone & 0.80 \\
salt & 0.30 \\
L-Lys·HCL, 98\% Lysine (Lys) & 0.20 \\
DL-methionine (Met) & 0.04 \\
vitamin and mineral premix & 1.00 \\
chemical composition & \\
digestive energy, Mcal· kg & -1 \\
Lys, \% & 3.28 \\
Met, \% & 1.17 \\
Analysed compostion, & 0.38 \\
CP, \% & \\
calcium, \% & 18.26 \\
total phosphorus, \% & 0.83 \\
\hline
\end{tabular}

${ }^{1}$ provided the following per $\mathrm{kg}$ of complete diet: IU: vit. A 2,000,0 vit. $D_{3}, 4,000$; mg: Fe 165, Cu 16.5, Mn 33, Zn 165, vit. E 30, vit. $K_{3}, 3$, vit. $\mathrm{B}_{2} 7$, vit. $\mathrm{B}_{6} 2$, pantothenic acid 10, niacin 15, biotin 0.08; $\mu \mathrm{g}$ : | 140, Se $297 ;{ }^{2}$ calculated based on the composition value of NRC (1998)

\section{Diarrhoea incidence}

The incidence of diarrhoea in piglets was observed and recorded 3 times per day during the study. The occurrence of diarrhoea was defined as maintaining definitely unformed faeces, moderately fluid faeces, or very watery and frothy diarrhoea. Diarrhoea incidence was calculated according to the formula (Huang et al., 2004):

diarrhoea incidence $(\%)=$ number of pigs with diarrhoea/(number of pigs $\times$ total experimental days) $\times 100$

'number of pigs with diarrhoea' was the total number of pigs with diarrhoea observed each day.

\section{Blood sampling and analysis}

Jugular venous blood samples ( $5 \mathrm{ml}$ per piglet) were withdrawn randomly from five healthy piglets per treatment group by venipuncture into $5 \mathrm{ml}$ vacuum blood connection tubes (Greiner Bio-One $\mathrm{GmbH}$, Gemmany) between 8.00 a.m and 10.00 a.m at the end of the experiment. Sera samples were obtained by centrifugation at $3000 \mathrm{rpm}$ for $20 \mathrm{~min}$ at $4^{\circ} \mathrm{C}$ and stored at $-20^{\circ} \mathrm{C}$. The level of antibodies against classical swine fever virus (CSFV) was measured by the commercially available ELISA 
HerdChek CSF test (IDEXX) according to the methodology described by the company. A blocking rate higher than or equal to $40 \%$ was considered positive, a sample was considered negative (without antibodies) if its blocking rate was lower than or equal to $30 \%$, and uncertain if the range was between $30 \%$ and $40 \%$. The serum concentrations of IL-2, IL-4, IL-10 and INF- $\gamma$ were measured using ELISA kits (Biocompare, South San Francisco, CA, USA) according to the manufacturer's instructions.

\section{Statistical analysis}

Data were analysed using one-way ANOVA (SAS Institute Inc., Cary, NC, 2002). The Tukey multiple comparison test was used to determine differences among the means of treatment groups. A probability value of $<0.05$ was considered statistically significant, and a value $<0.01$ was taken as highly statistically significant. For all tests, a pen served as the experimental unit.

\section{Results}

Growth performance. Over the entire experimental period, dietary supplementation of AVP at $0.1 \%$ increased ADG by $18.1 \%(P<0.05)$ compared with the control diet (Table 2). The ADFI of pigs fed diets with AVP at $0.05 \%, 0.1 \%$, and $0.2 \%$ were $2.3 \%, 14.9 \%$, and $8.6 \%$ greater $(P>0.05)$ than that of the control group, respectively. The F:G ratios of pigs fed diets with AVP were 2.2\%, 2.8\%, and $1.7 \%$ lower $(P>0.05)$ than of pigs fed the control diet, respectively.

\section{Change of diarrhoea incidence}

Diarrhoea occurred mainly during the second week of the experiment (d 8 to 14). The occurrence of diarrhoea lasted 2 to $4 \mathrm{~d}$. The incidence of diarrhoea was decreased in pigs fed diets with AVP $(P<0.01)$ compared with those fed the control diet (Table 2). There were no differences among the AVP treatments in diarrhoea incidence.

\section{Change of cytokine and CSF virus antibody levels}

In order to understand the effect of AVP on the responses of T cells, we first measured cytokines, including IFN- $\gamma$, IL-2, IL-4, and IL-10 in serum from the AVP-treated pigs. All of the data for cytokine analyses are shown in Table 3 . The serum levels of IL-2 and IL-4 increased significantly $(P<0.01)$ in all pigs fed the diet with AVP compared with the control group, and pigs fed either $0.1 \%$ or $0.2 \%$ had higher $(P<0.01)$ serum levels of IFN- $\gamma$, than that of control group, but IL-10 levels did not change in pigs fed AVP compared with the controls $(\mathrm{P}>0.05)$,
Table 2. Effects of dietary AVP on the growth performance and diarrhoea incidence of weaning pigs ${ }^{1}$

\begin{tabular}{|c|c|c|c|c|c|c|}
\hline \multirow{2}{*}{ Item } & \multicolumn{4}{|c|}{ Level of dietary AVP, \% } & \multirow{2}{*}{ SEM } & \multirow{2}{*}{$P$-value } \\
\hline & 0 & 0.05 & 0.1 & 0.2 & & \\
\hline \multicolumn{7}{|l|}{ Body weight, $\mathrm{kg}$} \\
\hline d 0 & 8.88 & $8 \quad 8.88$ & 38.88 & $8 \quad 8.87$ & 0.101 & 1.000 \\
\hline $\mathrm{d} 28$ & 21.58 & 822.22 & 223.88 & 822.86 & 0.344 & 0.094 \\
\hline$A D G, g, d 0$ to 28 & $454^{b}$ & $476^{\mathrm{ab}}$ & $536^{a}$ & $500^{a b}$ & 10.241 & 0.016 \\
\hline ADFI, g, d 0 to 28 & 807 & 826 & 927 & 877 & 18.420 & 0.081 \\
\hline$F: G, g / g, d ~ 0$ to 28 & 1.78 & B 1.74 & 1.73 & $3 \quad 1.75$ & 0.010 & 0.336 \\
\hline Diarrhoea incidence, $\%$ & $\% 14.2^{\mathrm{B}}$ & $7.1^{\mathrm{A}}$ & $6.6^{\mathrm{A}}$ & A $8.9^{A}$ & 0.886 & 0.002 \\
\hline
\end{tabular}

${ }^{a-b}$ means in the same row with different superscripts differ $(P<0.05)$; ${ }^{A-B}$ means in the same row with different superscripts differ $(P<0.01)$; 1 values are means of 5 individually caged pigs. $\mathrm{NC}=$ pigs in the control group were fed a basal diet; ADG - average daily gain; $A D F I$ - average daily feed intake, $F: G$ - feed:gain

Table 3. Effects of dietary AVP on the immune function of weaning pigs ${ }^{1}$

\begin{tabular}{|c|c|c|c|c|c|}
\hline \multirow{2}{*}{ Item } & \multicolumn{4}{|c|}{ Level of dietary AVP, $\%$} & \multirow{2}{*}{ - SEM $P$-value } \\
\hline & 0 & 0.05 & 0.1 & 0.2 & \\
\hline $\mathrm{IFN}-\mathrm{\gamma}, \mathrm{pg} \cdot \mathrm{ml}^{-1}$ & $62.62^{\mathrm{Cc} D}$ & D $68.42^{\mathrm{BC} C}$ & $76.26^{\mathrm{Bb}}$ & $94.64^{A}$ & $3.212<0.001$ \\
\hline $\mathrm{IL}-2, \mathrm{pg} \cdot \mathrm{ml}^{-1}$ & $103.98^{B}$ & $117.07^{\mathrm{Ab}}$ & $120.42^{\text {Aab }}$ & b $126.77^{\mathrm{Aa}}$ & $2.372<0.001$ \\
\hline $\mathrm{IL}-4, \mathrm{pg} \cdot \mathrm{ml}^{-1}$ & $47.54^{\mathrm{D}}$ & $68.19^{A}$ & $54.49^{B}$ & $52.75^{c}$ & $1.996<0.001$ \\
\hline $\mathrm{IL}-10, \mathrm{pg} \cdot \mathrm{ml}^{-1}$ & 110.77 & 113.43 & 111.50 & 112.55 & $1.195 \quad 0.894$ \\
\hline Blocking rate, $\%$ & $j^{2} 43.75^{c}$ & $85.00^{\mathrm{Aa}}$ & $72.25^{\mathrm{ABb}}$ & $62.00^{\mathrm{Bab}}$ & $4.128<0.001$ \\
\hline
\end{tabular}

${ }^{a-c}$ means in the same row with different superscripts differ $(P<0.05)$; ${ }^{A-D}$ means in the same row with different superscripts differ $(P<0.01) ;{ }^{1}$ values are means of 5 individually caged pigs. $\mathrm{NC}=$ pigs in the control group were fed a basal diet; ${ }^{2}$ serum was considered positive with a blockade percentage of $40 \%$ or higher

which indicates that AVP regulates serum cytokine levels in piglets. Antibodies, as products of the immune response play an important regulatory role in the humoral response. Changes of the CSF antibody blocking rate can reflect the state of humoral immunity accurately and directly. The serum antibody blocking rates of pigs in all groups are presented in Table 3. Compared with the control group, the blocking rates in all of the AVP-treated groups were significantly higher $(P<0.01)$, which demonstrates that AVP enhances the humoral immune response to classical pig fever live vaccine.

\section{Discussion}

Polysaccharides are found in abundance in nature and are readily available from sources such as algae (e.g., alginates), plants (e.g., pectin, guar gum, mannan), microbes (e.g., dextran, xanthan gum), and animals (e.g., chitosan, chondroitin). Also, they can be produced by means of recombinant DNA techniques. Complex carbohydrates obtained from natural sources (such as plants) have shown diverse 
biological activities, such as wound healing, enhancement of the reticuloendothelial system, stimulation of the immune system, treatment of tumors and effects on the haematopoietic system (Talmadge et al., 2004). Furthermore, several supplemental polysaccharides, such as Astragalus polysaccharide and Atractylodes macrocephala Koidz. polysaccharides, have been shown to improve the growth performance of young pigs (Yuan et al., 2006; Li et al., 2011). There is still little knowledge, however, of the possible benefits of AVP in weaned piglets. Aloe vera $\mathrm{L}$. is a perennial succulent xerophyte, which develops water storage tissue in the leaves to survive in dry areas of low or erratic rainfall (Hamman, 2008). Many of the medicinal effects of Aloe leaf extracts have been attributed to the polysaccharides found in the inner leaf parenchymatous tissue (Ni et al., 2004). In our preliminary experiment, weaned piglets (15 piglets per treatment without replication) were fed a diet supplemented with $0.02 \%$ and $0.05 \%$ AVP, respectively, and the results showed that the growth performance on $0.05 \%$ AVP supplementation was better than in the $0.02 \%$ group. Thus, three higher concentrations of AVP were used in the present study. Weaning is probably the most stressful time in the life of a pig and can lead to depressed feed intake and growth performance and to outbreaks of diarrhoea. Feed additives with high efficiency and low toxicity are being developed in order to boost the immune system and improve the host defenses of young pigs during weaning. In the present study, we found that supplementation with higher concentrations of AVP not only increased ADG, but decreased the incidence of diarrhoea as well.

A previous study showed that Aloe vera gel and whole-leaf extract were also able to significantly increase the transport of the macromolecular peptide drug, insulin, across Caco-2 cell monolayers (Chen, 2008). In other words, Aloe vera possesses a function enhancing the intestinal absorption of nutrients, which may be one of the possible mechanisms explaining the positive effects of AVP on the growth performance of piglets in this study. Phrase too long and not fully comprehensible.

Several hypotheses have been given for the mechanism of cytoprotection of Aloe vera, namely increased mucus synthesis, mucosal blood flow, and phospholipid content of the mucosal coating (Yusuf et al., 2004).

The polysaccharide content of the preparation used in this study was $48.55 \%$, the remaining ingredients consisted of other components of Aloe vera gel. It is believed that these biological activities should be attributed to the synergic action of the compounds contained therein rather than to a single chemical substance (Dagne et al., 2000). Anthraquinones isolated from the exudate of Aloe vera have shown broad antimicrobial activity. The antibacterial activity of emodin against Escherichia coli was proposed to be mediated through inhibition of solute transport in membranes (Hamman, 2008), which can offer an explanation for the decreased incidence of diarrhoea in weaned piglets.

It has been claimed that the polysaccharides in Aloe vera gel have therapeutic properties such as immunostimulation, anti-inflammatory effects, wound healing, promotion of radiation damage repair, anti-bacterial, anti-viral, anti-fungal, anti-diabetic and anti-neoplastic activities, stimulation of haematopoiesis, and anti-oxidant effects (Reynolds and Dweck, 1999; Talmadge et al., 2004). It has also been reported that the polysaccharides in Aloe vera gel have immunomodulating activities via activation of macrophages to generate nitric oxide, secrete cytokines (e.g., TNF- $\alpha$, IL-1, IL-6 or INF- $\gamma$ ), and express cell surface markers (Zhang and Tizard, 1996; Chow et al., 2005; Im et al., 2005). Aloeride, an immunostimulatory polysaccharide from commercial Aloe vera juice, has been characterized. Its molecular weight is between 4 and 7 million $\mathrm{Da}$, and its glycosyl components include glucose (37.2\%), galactose (23.9\%), mannose (19.5\%), and arabinose (10.3\%). Pugh et al. (2001) reported that aloeride increased $\mathrm{NF}-\kappa \mathrm{B}$ directed luciferase expression in THP-1 human monocytic cells to levels $50 \%$ of those achieved of LPS. Aloeride also induced the expression of the mRNAs encoding IL- $1 \beta$ and TNF- $\alpha$ to levels equal to those observed in cells maximally activated by LPS. Although aloeride comprises only $0.015 \%$ of Aloe juice dry weight, its potency for macrophage activation fully accounts for the activity of the crude juice (Pugh et al., 2001). Acemannan hydrogel, further refined, has been shown to act as an immunostimulant, displaying adjuvant activity in specific antibody production (t'Hart et al., 1989) and enhancing the release of IL-1, IL-6, TNF- $\alpha$, and INF- $\gamma$ (Peng et al., 1991).

Possible modulation of the immune response by AVP has been reported in humans (Marshall et al., 1993) and various animal species, such as broilers (Dai et al., 2007), mice (Yu et al. 2009) and cats (Šutovská, 2010). Reports on the effects of AVP on the immune response of weaned piglets are lacking, however. Cytokines are extremely important regulators of the T/B cell immune response, and antibodies can directly reflect the state of humoral immunity. In this study, we determined the effects of 
AVP on the production of cytokines and antibodies against CSF virus in the serum of weaned piglets fed AVP. We found that dietary supplementation with AVP increased the production of IFN- $\gamma$, IL-2, IL-4, and CSF virus antibodies, which demonstrated that the administration of AVP could regulate antibody and cytokine production in B and T lymphocytes. A detailed study on the CP7_E2alf marker vaccine and conventional $\mathrm{C}$-strain vaccine in piglets has been reported, in which it was shown that that the expression of the IL-10 gene was similar to that in control pigs after CP7_E2alf or C-strain vaccination (Renson et al., 2013), and our result concerning the levels of IL-10 in different treatments after vaccination, was not affected by AVP, which is agreement with this report. Renson et al. (2013) reported that the values of serum IFN- $\gamma$ and IL-4 were below the limits of detection both in serum by ELISA or in unpurified blood cells by relative quantitative rRT-PCR after vaccination or challenge with CSFV. In our experiment, however, serum IFN- $\gamma$ and IL-4 levels were detected in piglets after vaccination, possibly a result of AVP supplementation. IL-2 and IFN- $\gamma$ are cytokines representative for the Th1-response; these cytokines promote $\mathrm{T}$ cell activation, proliferation, and production of some cytokines. The activated T cell (e.g., Cytotoxic T Lymphocytes) can directly kill pathogens and plays an important role in the cellular immune response. Moreover, the problem if AVP as a feed additive can regulate the cellular immune response in pigs will be further studied. IL-4 as a Th2 marker cytokine can promote the production of specific antibodies by B cells. Therefore, the increase of CSFV antibodies in AVP-treated pigs might be related to the enhancement of IL-4.

\section{Conclusions}

In summary, our study suggests that Aloe vera polysaccharide (AVP), as an immunostimulator, can effectively promote the growth performance and enhance the immune function of weaned piglets. On the basis of the current study, AVP would be the most effective in improving the growth of nursery pigs when supplemented in the diet at a concentration of $0.1 \%$.

\section{Acknowledgements}

This study was funded by the Tianjin Natural Science Foundation (Grant No. 12JCQNJC09600) and Special Foundation of the President of the Tianjin Academy of Agricultural Sciences (Grant No 08030).

\section{References}

Chen W., 2008. Drug absorption enhancing properties of Aloe vera across the intestinal epithelium. D. Tech. Thesis, Tshwane University of Technology, South Africa

Chow J.T.-N., Williamson D.A., Yates K,M,, Goux W.J., 2005. Chemical characterisation of the immunomodulating polysaccharide of Aloe vera L. Carbohydr. Res., 340, 1131-1142

Dagne E., Bisrat D., Viljoen A., Van Wyk B.E., 2000. Chemistry of Aloe species. Curr. Org. Chem. 4, 1055-1078

Dai B.S., Jiang L., Chen S.X., 2007. Effects of medicinal herb and polysaccharide from Aloe on gut microflora, immune function and growth performance in broiler (in Chinese). China Poultry 29, 21-24

Hamman J.H., 2008. Composition and applications of aloe vera leaf Gel. Molecules 13, 1599-1616

Huang C.H. Qiao S.Y., Li D.F., Piao X.S., Ren J.P., 2004. Effects of lactobacilli on the performance, diarrhoea incidence, VFA concentration and gastrointestinal microbial flora of weaning pigs. Asian-Austr. J. Anim. Sci. 17, 401-409

Im S.A., Oh S.T., Song S., Kim M.R., Kim D.S., Woo S.S., Jo T.H., Park Y.I., Lee C.K., 2005. Identification of optimal molecular size of modified Aloe polysaccharides with maximum immunomodulatory activity. Int. Immunopharmacol. 5, 271-279

Li L.L., Yin F.G., Zhang B., Peng H.Z., Li F.N., Zhu N.S., Hou D.X., Yin Y.L., Luo J.J., Tang Z.R., Liu G., 2011. Dietary supplementation with Atractylodes Macrophala Koidz polysaccharides ameliorate metabolic status and improve immune function in early-weaned pigs. Livest. Sci. 142, 33-41

Marshall G.D., Gibbons A.S., Parnell L.S., 1993. Human cytokines induced by acemannan. J. Allergy Clin. Immunol. 91, 295

Ni Y., Turner D., Yates K.M., Tizard I., 2004. Isolation and characterisation of structural components of Aloe vera L. leaf pulp. Int. Immunopharmacol. 4, 1745-1755

NRC, 1998. Nutrient Requirements of Swine. $10^{\text {th }}$ revised Edition. National Academy Press. Washington, DC

Peng S.Y., Norman J., Curtin G., Corrier D., McDaniel H.R., Busbee D., 1991. Decreased mortality of Norman murine sarcoma in mice treated with the immunomodulator, Acemannan Mol. Biother. 3, 79-87

Pugh N., Ross S.A., Eisohly M.A., Pasco D.S., 2001. Characterization of Aloeride, a new high-molecular-weight polysaccharide from Aloe vera with potent immunostimulatory activity. J. Agr. Food Chem. 49, 1030-1034

Qi J.S., Liu Q.Y., Li X.H., Xiong J.L., Zhou A.M., Wei H., 2008. Aloe additives on the performance and meat quality of pigs (in Chinese). Sci. Technol. Inform. 14, 652-652

Renson P., Le Dimna M., Keranflech A., Cariolet R., Koenen F., Le Potier M. F., 2013. CP7_E2alf oral vaccination confers partial protection against early classical swine fever virus challenge and interferes with pathogeny-related cytokine responses. Vet. Res. 44, 9-19

Reynolds T., Dweck A.C., 1999. Aloe vera leaf gel: a review update. J. Ethnopharmacol. 68, 3-37

Šutovská M., 2010. Influence of polysaccharides from Aloe vera (Aloe barbadensis Miller, Liliaceae) on mechanically induced cough in cats. Acta Vet. Brno 79, 51-59

Talmadge J., Chavez J., Jacobs L., Munger C., Chinnah T., Chow J.T., Williamson D., Yates K., 2004. Fractionation of Aloe vera L. inner gel, purification and molecular profiling of activity. Int. Immunopharmacol. 4, 1757-1773

t'Hart L.A., van den Berg A.J., Kuis L., van Dijk H., Labadie R.P., 1989. An anti-complementary polysaccharide with immunological 
adjuvant activity from the leaf parenchyma gel of Aloe vera. Planta Med. 55, 509-512

Yin F.G., Yin Y.L., Kong X.F., Liu Y.L., He Q.H., Li T.J., Huang R.L., Hou Y.Q., Shu X.G., Tan L.X., Chen L.X., Gong J.H., Kim S.W., Wu G.Y., 2008. Dietary supplementation with Acanthopanax senticosus extract modulates gut microflora in weaned pigles. Asian-Austr. J. Anim. Sci. 21, 1330-1338

Yu Z.H., Che J., Ma X., He J.M., 2009. Effect of Aloe vera polysaccharides on immunity and antioxidant activities in oral ulcer animal models. Carbohyd. Polym. 75, 307-311
Yuan S.L., Piao. X.S., Li D.F., Kim S.W., Lee H.S., Guo P.F., 2006. Effects of dietary Astragalus polysaccharide on growth performance and immune function in weaned pigs. Anim. Sci. $82,501-507$

Yusuf S., Agunu A., Diana M., 2004. The effect of Aloe vera A. berger (Liliaceae) on gastric acid secretion and acute gastric mucosal injury in rats. J. Ethnopharmacol. 93, 33-37

Zhang L., Tizard I.R., 1996. Activation of a mouse macrophage cell line by acemannan: The major carbohydrate fraction from Aloe vera. Immunopharmacology 35, 119-128 